\title{
Books with No Indexes
}

By JED H. TAYLOR

A CARDINAL GOAL of librarians of institutions of higher learning is to build up collections of permanent value. For a non-fiction work to serve this purpose, we would expect it to be read in whole or in part and to be referred to for such things as facts, opinions, ideas, or felicitous phrasing. College librarians have to buy books selectively, a task made more difficult by the rising cost of books. ${ }^{1}$ It becomes more important, therefore, to acquire books which can be used both for reading and for reference. The key to the latter use is the index-the original information retrieval device.

Lorena Garloch states forthrightly that "books with no indexes at all are apparently written or published by egotists who feel that a book is only to be read through in its entirety. If it is ever to be referred to again, it must either be read through or the user must have such an uncanny memory that the needed passage can easily be found." 2 Isn't this all the more true for the librarian whose professional time is wasted inordinately by such books? Paul M. Angle in his article, "What! No Index?," 3 describes graphically this waste of time. He spent hours making a comparative study of a subject because, of the two books about it, the 1957 imprint had no index, although the 1918 imprint did.

"The continuing propensity of publishers to issue books (adult non-fiction) without indexes" 4 was first noticed by

1 "Book Prices," Library and Book Trade Annual: 1960 , edited by Wyllis E. Wright (Bowker, 1959), p. 53; for example, the prices of all economics hooks have increased 52.8 per cent between the $1947-49$ base period and 1958, according to a chart prepared by William $H$. Kurth.

2 Lorena Garloch, “Two, h, or not 2B?," Library Journal, LXXXIII' (1958), 3053.

3 Paul M. Angle, "What! No Index?," Library Jour. nal, IXXXIV (1959), 3387; taken in part from his article in Chicago History, V (1959), 218-222.
Mr. Taylor is Acquisitions Librarian, Mansfield State College Library, Mansfield, Pa.

the writer when scanning books in the cataloging process in a liberal arts college library. Lately, while checking several large shipments in a state college library, books without indexes seemed to be turning up with greater frequency. We discovered over three hundred, some two hundred of them published in the five years 1956-1960.

One hundred of the 1956-60 imprints were selected as typical of current books that college librarians might find it desirable to acquire. The books have been grouped in three categories: by formaddresses, essays and lectures, biography, collections, description and travel, literary criticism, pictorial works; by subject-contemporary scene, education, religion, science, miscellaneous; and by publishers-associations and agencies.

We did this to help us spot books which tend to be published with no indexes as a step in curtailing the purchasing of borderline books. We hope this review of our analysis will be useful to other librarians in the book selection process.

Addresses, Essays and Lectures. These are usually by men well known for mastery of the subjects about which they speak. Because of this fact, the references they use in support of their expositions become more significant, more authoritative. The authors, therefore, ought to index their works. Nevertheless, J. B. Fordham fails to do so for his development of the idea of $A$ Larger Concept of Community (Louisiana State 
University Press, 1956); nor does James B. Conant in his Godkin Lectures, Germany and Freedom (Harvard University Press, 1958). Yet, on a more general topic, Pieter Geyl, in his Terry Lectures, The Use and Abuse of History (Yale University Press, 1955), does include this essential feature.

Biography. For biographies, it would seem, indexes are prime requisites because the lives of men impinge on the lives of other persons and on events which are the primary interest of many readers. Illustrative are these worksone about the past, one about the present: New England Saints (University of Michigan Press, 1956), by Austin Warren, and Nikolai Khokhlov's In the Name of Conscience (McKay, 1959), "the testament of a Soviet secret agent." The value of the works is seriously reduced because there are no page references to persons or to events.

Collections. Perhaps collections are less likely to need indexes because they comprise excerpts from the works of one or more authors. However, one would have to read one or more chapters, depending on the illusive accuracy of their titles, to track down specific information. This is exactly what Angle ${ }^{5}$ had to do to trace the movements of a female detective in Secret Missions of the Givil War (Rand, McNally, 1959), by Philip Van Doren Stern. Certainly, source books, being used primarily for reference, should have indexes. It is regrettable, therefore, that The Renaissance Stage (University of Miami Press, 1959), edited by Bernard W. Hewitt, is an indexless collection of documents.

Of course, The Essay Index and The Biography Index cover many collections by authors and titles and under broad subjects. These are estimable tools to find excerpts for first reading, but statements within chapters are beyond the scope of these indexes.

Description And Travel. Travel books

$$
5 \text { Op. cit. }
$$

need indexes to answer the questions Who?, What?, When?, Where? Our experience indicates that too often they do not. For example, a description of Israel (Hill \& Wang, 1958), by Ruth Gruber, is deficient in this vital respect. Gavin Maxwell's The People of the Reeds (Harper, 1957), describes the culture of a tribe inhabiting the marshes of the Tigris River. Yet the legitimate interest of social scientists in specific aspects of this culture is foreclosed by lack of an index.

Literary Criticism. One would think it would be standard procedure for scholars to furnish indexes so that their peers could check on sources and findings. It is not uncommon, however, to find works like Robert M. Adam's Stendahl (Noonday Press, 1959), which does not do this. And does it not seem presumptuous for Margaret Kennedy, author of The Outlaws of Parnassus (Viking, 1960) to expect all readers to take "an excursion among novelists from Homer to the moderns" without an index?

Pictorial Works. At first glance, pictorial works would seem to be the type least likely to require indexing. But reference librarians know how difficult it can be to answer requests for visual representation of persons, places, things. There is no index to these in an expensive book, Africa (Simon \& Schuster, 1959), by Emil Schulthess-no way to relate his pictures to the actualities of today.

Contemporary Scene. This is the first heading for titles grouped by subject. When considering similar titles on the same subject, as often happens, a selection may well turn on a comparison of bibliographical features, of which the index is a major one.

Writers on the contemporary scene seek to inform, to influence opinion, to change attitudes; the last is particularly

(Continued on page 261) 


\section{... No Indexes}

(Continued from page 230)

the aim of authors who write in a philosophical vein. One would expect them, especially, to assume that their works will be quoted. The index means to this end, surprisingly enough, is omitted by Jacques Barzun in The House of Intellect (Harper, 1959). In The Fourth Branch of Government (Houghton, 1959), Douglas Gator is concerned about pressgovernmental relations in Washington, but is unconcerned about leaving the intricacies of these relationships unindexed. On the contemporary scene abroad, Chester Bowles in 1956 wrote a fact-crammed work, Africa's Challenge to America (University of California Press). Obviously, the challenge is greater now than then. And when we turn to it for certain facts, we find no way to retrieve the information.

Education. Books on education may be of general interest or for specialists. Books of both kinds come without indexes; such as Soviet Education Today (De Graff, 1959), by Deanna Levin and Visual Methods in Education (Philosophical Library, 1957), by William C. Sumner. In Undercover Teacher (Doubleday, 1960), George N. Allen treats factually conditions which Evan Hunter treats fictionally in The Blackboard Jungle (Simon \& Schuster, 1954). But the former, without an index, has no more reference value than the latter.

Religion. One can understand, perhaps, index omissions in books of exhortation. But differences of opinion are common in the field of religion, and it seems that authors would be sure to include indexes to their interpretations. Libuse Miller neglects to do this in The Christian and the World of Unbelief (Abingdon, 1957); nor does A. C. Bouquet provide an index to Christian Faith and Non-Christian Religions (Harper, 1958).

ScIENCE. Depending upon the subject treated, the college public is, at one and the same time, both professional and lay. In either role, this public tends to channel its subject curiosity; therefore, it needs indexes to particulars which interest it. Examples of works which do not meet this need are: Scientific Uses of Earth Satellites (University of Michigan Press, 1958), edited by James Van Allen, and Galaxies to Man (Random House, 1959), by John Pfeiffer.

Miscellaneous. There are many titles which lack enough common characteristics to disclose categories other than the foregoing ones. We have in mind titles which, in treatment, come within the purview of college library requirements. The books cover a variety of subjects-Islamic law, retarded children, philately, demonology. Here are two which one would assume would have indexes but do not: Foundations of Capitalism (Philosophical Library, 1959), by Oliver C. Cox, and Harold M. Mayer's Port of Chicago and the St. Lawrence Seaway (University of Chicago Press), which is the 1957 imprint that caused Angle $^{6}$ so much trouble.

Associations And Agencies. This heading segregates titles published by such organizations. As collective action increases, the number of titles issued or sponsored by organizations increases. Many of these publications are reports of the latest findings and developments in the various disciplines; many are continuations. For some agencies, as departments of universities, no indexes are due to limited budgets. ${ }^{7}$ Associations and agencies may also omit indexes because they sell at low prices. ${ }^{8}$ There should be a greater opportunity to effect improve-

6 Op. cit

7 Ernest Q. Campbell and others, When a City Closes Its Schools (Chapel Hill, N. C.: Institute for Research in Social Science, University of North Carolina, 1960), $195 \mathrm{p}$. $\$ 1.00$ paper.

${ }^{8}$ William Kvaraceus and others, Delinquent Behavior Culture and the Individual. (Washington D. C.: Juvenile Delinquency Project. National Education Association, $1959), 147$ p. $\$ 1.25$; and National Reading Conference, Starting and Improving College Reading Programs the 8th Yearbook of the Conference; edited by Oscar Causey and William Ellen. (Fort Worth: The Conference, Bailey Building, Texas Christian University 1959), 196p. \$2.50 paper. 
ments with the cooperation of their officials because so many are members of the academic community and because libraries of institutions of higher learning probably constitute their best market.

The writer hopes that librarians will be interested in checking for books without indexes among their recent acquisitions. Their search may locate other titles under the headings used here or accumulate titles which fall within other categories. If this should be the case, we can conclude that many titles are being acquired that do not meet the index criterion of permanent value. As time passes, it seems that books now current are less likely to be widely read and more likely to be used as sources for later scholarly research; hence the need for indexes.

At least, a non-indexed work serves notice to the searcher that he is "on his own." But a poor index perpetrates a kind of literary fraud in that it can lead the unwary reader to infer that there is nothing in a work on his or her problem. Garloch's article ${ }^{9}$ on inadequate indexing has been cited, and librarians know that their representatives on the Z39 Subcommittee of the American Standards Association helped to draft the standards adopted by this Association. ${ }^{10}$ The standards need to be adapted for daily use by book selectors. One way might be to devise indicators of thoroughness which can be applied to various types of books categorized by form, content, readers, etc.

The index is important, but it is not the only feature of the bibliographic apparatus (broadly defined). Its best features are standards of good practice which contribute to a reader's understanding and which enable a searcher to find most readily data pertinent to his inquiry and make possible his recourse to other sources with the least delay.

${ }_{10}^{9}$ Op. cit., 3051-3055.

10 "Z39 Subcommittee on Indexing; American Standards Association: Report, 1958," ' Library Journal,
Experience suggests that any search, taking no more time than that for this article, will as surely disclose instances of sub-standard practice. Illustrative is The Goals of Higher Education (Harvard University Press, 1960), edited by W. D. Weatherford, Jr. It is a collection of lectures by six prominent educators. None, except Gordon Allport, gives footnotes or citations. These markedly increase the scope of the one lecture, leading readers to citations of works with more data on the facets of Allport's subject of interest to them.

We share with scholars an interest in this deteriorative situation but, more directly, because librarianship is concerned with the relative quality of a title, both as book and work, whatever the subject, which is the primary interest of the scholar. Therefore, it might be appropriate for librarians to consider initially the improvement of the apparatus. A committee of librarians could do the groundwork by offering conclusive evidence of the deterioration. Such action will bring librarians in contact with professors on the campus and as officials of their associations. We should be able to arouse their interest by making them aware of the increasing difficulty they will encounter in their research due to the faulty bibliographic apparatus of more and more books.

For maximum effectiveness, any steps to bring about improvements in the situation would probably have to be done by a joint committee of librarians and scholars. Their prestige will aid immeasurably because the improvements themselves must come from action by their own brethren, by other writers, and by publishers. But with publishers librarians should have not inconsiderable influence for, as they admit, the library market absorbs "a good half of their adult non-fiction (best-sellers and reprints aside)."11

"Daniel Melcher, "The Library Market," American Library and Book Trade Annual, 1960, edited by Wyllis
E. Wright (New York: Bowker, 1959), p. 43 . 
The cooperation of librarians and scholars may not be without its difficulties because the approach of each to the problem is different: the librarian, that of the generalist; the scholar, that of the subject specialist. If, however, both work together to improve the apparatus which benefits scholars personally, then one might not be overly optimistic to expect further support from them in building collections of permanent value. They should see that this, too, is to their advantage for, after all, the product with which we deal comes largely from their hands.

Readers interested in pursuing this matter further can obtain on request to the writer a bibliography of one hundred non-indexed titles published in the five-year period 1956-1960 arranged alphabetically by author under the headings used in this article.

THE SATURDAY REVIEW SAYS:

"A great and needed work ..."

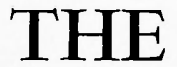

\section{INTERPRETER'S BIBLE}

One of the most popular, most comprehensive commentaries available today. Double text, exegesis, exposition all on the Working Page; plus Introductions, exhaustive General Articles, maps, charts and photographic illustrations.

12-volume set, $\$ \mathbf{8 9 . 5 0}$

Each volume. $\$ \mathbf{8 . 7 5}$

\section{ABINGDON PRESS} NASHVILLE 2, TENNESSEE

In Canada: G. R. Welch Company, Ltd., Toronto

In Australasia: Thomas C. Lothian, Melbourne

\section{The Definitive Index}

\author{
of the entire \\ aerospace field
}

\section{THE PACIFIC AEROSPACE LIBRARY UNITERM INDEX}

finds the exact technical material you want from more than 300 English language scientific periodicals covering:

aerodynamics $\cdot$ missile design $\cdot$ rocketry $\cdot$ astronautics $\cdot$ nuclear physics - metallurgy $\cdot$ communications $\cdot$ data acquisition and processing - mathematics - radar - computers - physics - automation - electronics - physical chemistry $\cdot$ aviation medicine $\cdot$ plastics - ceramics - ordnance - production $\cdot$ management

Material is located rapidly with pin-point accuracy. Sources include translations of Russian journals and other publications of worldwide scope.

The UNITERM INDEX is unique in its field; more than $50 \%$ of the periodicals indexed do not appear in any other cumulative index. It is not bulky, complete in its binder it weighs only $31 \%$ pounds.

One Year's service-cumulated bymonthly

$\$ 250.00$

obtainable from

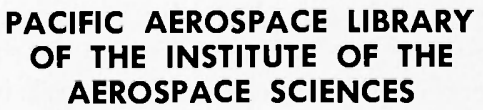

7660 Beverly Blvd. Los Angeles 36, California 